\title{
Leaving Home, Entering Institutions: Implications for Home-Leaving in the Transition to Adulthood
}

\author{
Youngmin $\mathrm{Yi}^{1}$ \\ Department of Sociology \\ Department of Policy Analysis \& Management \\ Cornell University \\ yy567@cornell.edu
}

\begin{abstract}
The departure from the parental home is an important milestone in the transition to adulthood. However, studies of the timing, prevalence, and nature of home-leaving do not generally incorporate the full range of experiences that young adults increasingly face- - such as military service and incarceration. With the growing prevalence and uneven distribution of these institutional experiences, consideration of the role these institutions play in the home-leaving transition becomes increasingly important to our understanding of this life event. This study uses life table analysis of the 1997 National Longitudinal Survey of Youth to compare estimates of the timing and cumulative risk of first home-leaving by age 27 using conventional and institution-inclusive definitions of home-leaving. I find that the institution-inclusive definition of home-leaving yields earlier and higher overall risks of first home-leaving by age 27 and that there is meaningful racial/ethnic variation in the types of transitions young adults make when they leave the parental home for the first time.
\end{abstract}

\footnotetext{
1 The author would like to thank Christopher Wildeman, Daniel Lichter, Matthew Hall, Erin York Cornwell, Megan Doherty Bea, Alyssa Goldman, and Emily Sandusky for their thoughtful feedback on earlier iterations of this work. Please direct any correspondence to Youngmin Yi via mail at 323 Uris Hall, Cornell University, Ithaca, NY 14853 or via email at yy567@cornell.edu.
} 
The transition to adulthood is a stage of the life course during which young adults become increasingly independent from their parents and childhood contexts. In the United States, one of the events associated with this life stage is the departure from the parental home (Furstenberg et al. 2004; Settersten and Ray 2010). A large multidisciplinary body of research has extensively detailed the many facets of this transition including its timing and prevalence and changes therein associated with broader social shifts such as women's entry into the labor force (e.g. Goldscheider and Goldscheider 1999; van den Berg, Kalmijn, and Leopold 2018). These studies have focused nearly exclusively on parental co-residence and family/household formation, with limited engagement of the implications of contact with institutions such as the military, the criminal justice system, and postsecondary education on this milestone. In this study, I suggest that an institutional perspective that combines our exploration of dynamics around the parental home with our knowledge of the expansion and unequal distribution of young adults' institutional contact is important to our understanding of stratification early in the life course.

Recent trends in the transition to adulthood provide compelling empirical motivation for revisiting the way we define home-leaving. First, patterns of parental co-residence and homeleaving have changed: parental co-residence in one’s twenties is now a common experience (e.g. Furstenberg 2010; Vespa 2017). Second, over recent decades, the criminal justice and higher education systems, two key social institutions with residential aspects (e.g. on-campus housing and prisons), have expanded rapidly and penetrated early life and adulthood to a degree that is historically unprecedented (Pettit and Western 2004; Wakefield and Wildeman 2013). This institutional reach is uneven in its impact on the transition to adulthood across social group, particularly with respect to race and socioeconomic status (Pettit and Western 2004; Rumbaut 2007), and shapes later life outcomes, including residential attainment and housing (in)security 
(Massoglia, Firebaugh, and Warner 2013; Herbert, Morenoff, and Harding 2015; Warner 2015).

As these trends continue to unfold, the consideration of the simultaneity of these experiences becomes increasingly important to our understanding of the transition to adulthood.

This study uses a descriptive cohort life table and multinomial regression analysis of the 1997 National Longitudinal Survey of Youth (NLSY97; U.S. Bureau of Labor Statistics 2015) to (1) illustrate the impact of the inclusion of institutions on our estimation of the timing and cumulative risk of first home-leaving in the transition to adulthood and (2) examine racial/ethnic differences in the nature of first departures experienced in this life stage. The core of this analysis is the comparison of "roster-based" and "institution-inclusive" measures of homeleaving, the latter of which includes departures for postsecondary education, military service and training, and incarceration, to show how different definitions of home-leaving provide different insights about the timing and nature of that life event and patterns across social groups.

In this analysis of U.S. resident young adults, I find that an institution-inclusive perspective yields higher cumulative risk estimates of young adults' first home-leaving by age 27. Analysis of this measure also finds that young adults first depart from the parental home earlier in the life course than as described by a standard household-based definition of the event of first home-leaving. Additionally, in using an institution-inclusive measure of home-leaving I find that the contexts to which young adults first leave the parental home differ across racial/ethnic groups. Hispanic young adults are less likely than those who are White or Black to leave the parental home for the first time for college and more likely to leave to establish or enter living arrangements with non-parental others. Black young adults are more likely than White and Hispanic young adults to leave the parental home for the first time for incarceration. 


\section{THEORETICAL BACKGROUND}

\section{Leaving the Parental Home}

Home-leaving in the transition to adulthood has long been a core topic for those examining the life course and wellbeing in early life and young adulthood (Goldscheider et al. 1999; Guttman, Pullum-Piñón, and Pullum 2002). This body of work estimates the timing and overall prevalence of this transition, detailing socioeconomic, gender, and racial/ethnic variation therein (e.g. Seltzer and Bianchi 2013; White 1994). Studies vary somewhat in their measurement of home-leaving and have explored shifts in the nature of this transition as a component and reflection of social, cultural, and economic change. For example, beginning in the 1970s, home-leaving grew increasingly associated with events other than marriage—such as entry into employment and non-marital cohabitation-motivating an updated exploration of the precipitating events and conditions around departures from the parental home (e.g. Goldscheider and Goldscheider 1999; Kahn, García-Manglano, and Goldscheider 2017).

Taken together, this literature finds that although the vast majority of young adults have left the parental home at least once in the transition to adulthood (e.g. Dey and Pierret 2014), the timing of this departure varies across social groups (Furstenberg et al. 2004; Settersten and Ray 2010). Further, there have been increases in the rates of returns and repeat departures out of the parental home, a phenomenon or process often referenced as "boomeranging," of particular interest with the constraints felt by young adults facing expanding student debt burdens and the fallout of the Great Recession (Houle and Warner 2017; Sandberg-Thoma, Snyder, and Jang 2015; Wiemers 2014). This research finds that Black, Hispanic, and economically disadvantaged young are more likely to be living with parents in adulthood and likely to be leaving the parental 
home later than their White and more advantaged peers (e.g. Britton 2013; Houle and Warner 2017; Lei and South 2016; Sandberg-Thoma et al. 2015; Treas and Batalova 2011; White 1994).

Contemporary definitions of what constitutes a departure from the parental home range from stricter definitions that specifically equate it with the establishment of an independent residence (e.g. Buck and Scott 1993) to broader ones that include temporary or "semiindependent” states of departure such as leaving for college or to live with non-romantic, nonfamilial roommates (e.g. Goldscheider and DaVanzo 1989; Houle and Warner 2017). Our definitions and descriptions of parental co-residence, therefore, implicitly reflect our ideas of what it means to be an adult and the roles and living arrangements that are reflective of this "status.” As such, delays in transitions away from one’s childhood family are often also interpreted as and linked to delays in transitions into adult roles and responsibilities (Berzin and DeMarco 2010; Qian 2012). For example, although home-leaving research has always considered co-residence with a marital partner to be an "adult” living arrangement, studies often question the "adulthood" of an adult in other non-romantic co-residential arrangements in their identification of home-leaving, although some of these arrangements are not uncommon among adults in the U.S. today (i.e. living with non-relatives; U.S. Census Bureau 2018).

\section{Institutions in the Transition to Adulthood}

If we recognize the sociocultural contingency of the definition and measurement of home-leaving, we can also reconsider the role of non-familial/household institutions in our analysis and description of the home-leaving experience. Families and households are not the only institutions in which young adults become embedded during this stage of the life course, not the only institutions that affect their living arrangements and residential trajectories, and not the only institutions that structure their initial and consequential social roles and positions in 
adulthood. With age, the adolescent or young adult is more likely to come into contact with these other institutions.

More specifically, as people reach age 18 in the United States, they become eligible for military service, can enroll in postsecondary institutions, are automatically treated as adults in the criminal justice system (and thus at higher risk of incarceration), and leave the legal responsibilities of their childhood caregivers and parents. With the expansion of the pursuit of postsecondary education and the reach of the criminal justice system, likelihoods and risks of entry into these social contexts have increased across the board, although differentially so for young people of different social backgrounds. For example, while upper- and middle-income White women are more likely than those of other racial and socioeconomic groups to go to college and to move away in pursuit of postsecondary degrees (DiPrete and Buchmann 2006; Ovink and Kalogrides 2015), low-income Black men, are more likely to go to jail or prison than those of other groups (Pettit and Western 2004).

These experiences and institutional transitions have long been studied as part of young people's entry into adult social positions and roles over the life course—such as entry into military service, perception and treatment as adults in the eye of the law, and matriculation into postsecondary schooling for training in the adult workforce (e.g. Hogan and Astone 1986; Kelty, Kelykamp, and Segal 2010; Rumbaut 2007). However, these “institutional transitions” have largely been examined independently of the home-leaving experience, although they, like departures from the parental home to new families and households, are linked to transitions into adult roles and responsibilities and have consequences for residential trajectories over the life course (Britton 2013; Massoglia, Firebaugh, and Warner 2013; Raphael 2007; Warner 2015). 


\section{Conceptualization and Measurement of Home-Leaving Events}

This disconnect between bodies of work studying home-leaving and other institutions in the transition to adulthood is in part due to our conceptualization of home-leaving and what types of life events constitute a transition away from the home. However, the relative lack of attention to the interaction between these social institutions and home-leaving pathways is also in part due to the characteristics of the data currently available to look at these residential patterns. Goldscheider and Waite $(1993,219)$ provide a detailed discussion of this feature of the 19661980 National Longitudinal Surveys of Young Men and Young Women (NLS), noting the postsurvey linkage of respondents back to primary residences and the need to take this into consideration when examining young adults' residential mobility; this is a featured shared with the broader family of NLS studies analyzed extensively in research on home-leaving.

In the 1979 and 1997 National Longitudinal Surveys of Youth (NLSY), for example, if a respondent was not in the primary residence because they were away at college at the time of interview, the linking process still reported them as co-residing with the individuals named in the household roster of the primary residence on record, although the criteria for an NLSY79 respondent to qualify as "independent" includes enrollment in a 4-year college at the time of survey (BLS Undated; Goldscheider and Waite 1993). This is in some ways an indicator of incongruence between our conceptualization of adulthood/independence and how it is or is not reflected in our measurement of other events that mark the transition to adulthood.

Standard practices in home-leaving research, then, often mark periods of incarceration, military barracks, or entry into shared living arrangements in college during the transition to adulthood as time still in the parental home, although these very experiences are considered markers of or turning points into adulthood. The degree to which this is a concern or challenge 
for research on the transition to adulthood varies by study objective. If focused strictly on household and family formation, this may be a non-issue. However, there are a couple key reasons to revisit the standard definition and measurement of departures from the parental home.

First, there is much evidence that the transition to adulthood is changing as a function of contact with social institutions beyond the family and household. This is similar to the role that college-going and the rise of women's labor force participation played in the changing departure from the parental home in the mid- and late- $20^{\text {th }}$ century. Second, entry into these institutions plays a role in shaping residential attainment and trajectories in ways that are consequential for events and milestones such as family and household formation that have long motivated studies of home-leaving. A reconsideration of approaches to measuring and defining home-leaving could serve to update our view of this event to reflect the diverse ways in which young adults move in and out of their childhood homes and provide di insights about the relationship between institutions and living arrangements of young adults in this critical stage of the life course.

This study explores one alternative way to expand our definition of home-leaving to account for institutional contact in the transition to adulthood and demonstrates how different definitions of this experience yield different conclusions about the departure from the parental home. I focus on two key questions: first, how does the inclusion of institutional transitions into our measurement of home-leaving shape our understanding of the timing and overall risk of first departures from the parental home? Second, do conclusions about inequality in home-leaving experiences differ across the two measures, and, if so, how?

I anticipate that the inclusion of institutional transitions will yield higher overall estimates of first home-leaving in the transition to adulthood and earlier average rates of home-leaving. Given racial/ethnic differences in matriculation into college/university, military enlistment, and 
criminal justice system contact, I also expect that the inclusion of institutions in the definition of home-leaving events will allow us to identify racial variation in young adults' pathways out of the parental home.

\section{Data, MeAsures, AND Methods}

\section{Data and Sample}

To examine the home-leaving experiences of young adults of different socioeconomic and racial/ethnic backgrounds, I draw on a data set that has been used extensively for studies of home-leaving: the 1997 National Longitudinal Survey of Youth (NLSY97). These data are furnished by the U.S. Bureau of Labor Statistics and follow a cohort of individuals that is nationally representative of the U.S. civilian non-institutionalized population aged 12-17 in 1997 (U.S. Bureau of Labor Statistics 2015). The NLSY97 surveys young adults as they move through into early adulthood and collects detailed information about their household and residential situations, making it especially appropriate for this study of residential experiences in the transition to adulthood. The current analyses follow these individuals annually through 2011, when the respondents were aged 26 to 32 years. In 2011, the NLSY97 data transitioned to a biennial survey; to ensure consistent time intervals for measurement of residential situations, I do not follow individuals beyond that year.

The analytic sample is restricted to those with information on their own race and ethnicity and sex and at least one parent's educational attainment, resulting in a loss of 698 respondents. A parent is defined here as a biological, adoptive, or step-parent of the youth respondent. I also restrict the analysis to those who reported living with at least one parent in the first round$97.4 \%$ of all respondents met this criterion—which leads to an additional loss of four respondents. The sample is restricted further to those who are observed at three points in time: at 
baseline (1997), in 2011, and at least once in between, resulting in a final analytic sample of 6,843 individuals, or 76\% of the full baseline NLSY97 sample of 8,984 individuals.

\section{Measuring First Departures from the Parental Home}

I compare two different measurements of departures from the parental home, called the rosterbased and institutional-inclusive measures. For the roster-based approach, young adults are coded as living with a parent(s) at each year of the survey if they name at least one parent in the household roster in that round. I also determine whether the respondent is the owner or renter of the housing unit; if they report living with a parent but are themselves the homeowner/renter, they are designated as not living with their parents. This is consistent with prior work that uses independent/own residence as the basis for identification of a home-leaving event (e.g. Ruggles 2007; Sandberg-Thoma, Snyder, and Jang 2015).

The second approach, the institution-inclusive measure, modifies the practice of linking youth back to primary residences in the NLSY97 by incorporating information about other respondent statuses and experiences at the time of survey that affect their residential conditions but are not captured by the household roster. Beginning with the same foundation as the rosterbased measure, I use an array of additional measures that describe the respondent's residential context in more detail. This information allows me to determine whether the individual is currently incarcerated (jail, prison, or detention in a work release program); living somewhere else for postsecondary education (dormitories, fraternities, sororities, university-sponsored rental units); living in military barracks for training or service; living in a group home, treatment center, or shelter; has become an independent householder (renting or owning residential property); or is no longer alive. Those who are identified in the household roster as having left the parental home but not for one of these institutional transitions is described as having left for 
any "other reason.” These categories are mutually exclusive, meaning that an individual can only experience a first transition from the parental home via one of these pathways.

A noteworthy distinction between the unlinked operationalization of home-leaving and those observed in prior work on this topic is that in my analysis, the categories of establishing one’s own household (“independent”) and “other" capture the types of departures that often comprise the focus of home-leaving research, such as departures to relocate to establish one's own household—including one shared with parents but in which the young adult is the householder—or moving in with other adult room or housemates. However, in this institutioninclusive measurement, those who report living in housing for postsecondary schooling, incarceration facility, military housing, in an independent household, or group home/treatment center/shelter are coded as having left the parental home, although the roster for the household to which they are linked may indicate the presence of a parental figure. In the roster-based approach, by contrast, these individuals would be identified as living with their parents at the time of survey if the primary household of note included a parent (Goldscheider and Waite 1993). By incorporating institutional transitions, this measurement may provide a richer depiction of the living arrangements and diversity of social positions and contexts, favorable or not, that characterize early adulthood in the United States.

\section{Key Characteristics}

In addition to exploring the implications of this conceptual shift for our understanding of overall patterns of home-leaving in the transition to adulthood, I am interested in examining sociodemographic variation in home-leaving generally and in the consequences of incorporating institutional transitions as part of this experience. In this study, I therefore also examine homeleaving risks and pathways with respect to racial/ethnic identification and parental education, 
accounting also for differences with respect to sex. A respondent's race/ethnicity is captured using measures of the child's self-reported race and Hispanic ethnicity to be grouped into one of the following mutually-exclusive categories: non-Hispanic White, non-Hispanic Black, Hispanic, and non-Hispanic other race.

I use parental education as an indicator of socioeconomic background. Parental education is a dichotomous measure of respondents' parents' education in years. Educational attainment information for both biological and residential parents are available in the NLSY97; to maximize completeness of information on parental education in these analyses, parental education was identified for whichever type of parent (biological or residential in cases where the two were not the same) for whom that information was available. Finally, sex is a dichotomous indicator that notes whether the respondent was identified as male or female at baseline. As the NLSY97 survey instrument uses the term "sex" rather than "gender" for this item, I use the term “sex," as well (U.S. Bureau of Labor Statistics 2012).

\section{Analytical Approach}

To examine how an institution-inclusive definition and conceptualization of home-leaving might impact our understanding of the timing and prevalence of first departures from the parental home in the transition to adulthood, I use birth cohort life tables (Preston, Heuveline, and Guillot 2001). Life tables were originally and have most often been used to examine mortality and health over the life span but can also be used to study other events. Examples of other applications of this method include studies of entry into poverty (Rank and Hirschl 1999) and children's risks of foster care placement (Wildeman and Emanuel 2014).

In this study, the event of interest is the respondents' first departure from the parental home, measured annually at the time of survey in the NLSY97. I determine whether the 
respondent has yet left their parents' home for the first time at each age using the roster-based and institution-inclusive measures described above to construct two separate sets of life tables. In both life tables, a respondent remains a member of the sample "at risk" of first home-leaving in the next age interval of the life table until the year/age at which they are first identified as being absent from the parental home. Upon first measurement as having left the parental home, they are removed from the "risk pool" of potential first-time home-leavers for the subsequent age interval. For example, if an individual, entering the study at age 18 is identified as living in the parental home at ages 19 and 20, they will remain in the denominator of the risk estimate for the whole sample at ages 19 and 20. When they are then identified in the data as being out of the parental home at age 21, they are removed from the sample at risk of first departure for the rest of the study period.

Aggregating up from these individual-level identifiers of parental co-residence, I calculate age-specific counts of those leaving the parental home for the first time, those at risk of doing so, and those who are no longer at risk. These three pieces of information form the basis of the hazard functions that yield age-specific and cumulative risks of first departure by age 27 and the core of the life tables. The life tables begin at 14 because no respondents who were living with at least one parent at the first round of the survey reported leaving the parental home before age 14, either because they are not observed at that age or are observed but do not experience a residential transition before 14 . They end at 27 , the oldest age through which all respondents have aged by the 2011 NLSY survey year. Those who are observed beyond that age and report leaving the parental home for the first time after the age of 27 are coded in the life tables as not having left by the end of the study period. 
The analysis centers on the construction of single decrement cohort life tables as described above, to estimate cumulative risks of first departures from the parental home using the roster-based measure of home-leaving that relies primarily on the NLSY97 household roster to determine parental co-residential status. In the second stage of the analysis, I again estimate cumulative risks of first home-leaving but with the institution-inclusive measure that includes residential transitions for higher education, military service, incarceration, independent living (own rental/owned housing), and another institution (group home, treatment center, shelter). Confidence intervals around the two sets of risk estimates allow me to assess whether the inclusion of institution-related transitions do ultimately affect measurement of the timing of first home-leaving. For both sets of life table estimates, I account for exit from the NLSY97 study due to the respondent's passing between survey rounds; ultimately, this does not affect the analyses as all respondents in the analytic sample leave the parental home via another experience prior to any recorded exit from the survey due to death.

In addition to estimating these risks for the overall sample, I estimate risks specific to racial/ethnic groups to explore how this expanded definition of home-leaving and institutional contact, more specifically, might differentially impact our understanding of this life transition for young adults of different sociodemographic groups. Estimates based on analysis of all respondents are weighted to account for the complex sampling design of the NLSY97 in producing overall estimates of home-leaving. For subgroup-specific analyses, however, I report unweighted estimates. These analyses account directly for dimensions along which the NLSY97 sampling weights are based by stratifying with respect to race/ethnicity; as such, I refrain from applying sampling weights to these race/ethnicity-specific risk estimates (Bollen et al. 2016; Solon, Haider, and Wooldridge 2015). To assess whether cumulative risk estimates are 
statistically distinguishable across measures and between racial/ethnic groups, I estimate 95\% confidence intervals using Greenwood's method (Greenwood 1926).

Finally, to examine variation in the types of institutional transitions that young adults make, I use unweighted multinomial logistic models to estimate the likelihood that an individual's first residential context away from the parental home is one other than an independent household (own/rent, single/shared) as a function of their racial/ethnic group. To examine these associations, I estimate two models: (1) a baseline model that models homeleaving pathway as a function of one's racial/ethnic group as well as their age at baseline and the number of times they are observed in the study period and (2) a full model that adjusts for respondent's sex and parental education. As the purpose of the current study is to provide a description of the implications of institutional transitions for home-leaving in the transition to adulthood, the estimated models in this analysis are kept parsimonious.

\section{RESULTS}

A weighted statistical description of the sample is presented in Table 1. The top panel of the table shows that just under half of the sample identified as female and that the majority of the sample identified as non-Hispanic White (68\%). 14 percent and 13 percent of the analytic sample identified as non-Hispanic Black and Hispanic, respectively. These individuals’ average maximum level of parental education was 13 years of schooling. The average analytic sample member was 14 years old at the time of the start of the NLSY97 and was observed for nearly all rounds of the survey examined in this analysis (13 rounds). A comparison of the characteristics of the analytic sample and the full NLSY97 sample shows that the two are extremely statistically similar (see Appendix Table A1). 
The bottom panel presents a description of these individuals' initial transitions out of the parental home, as captured by the two measures of home-leaving described above. The institution-inclusive measure estimates that a higher proportion of young adults have left the parental home for the first time by age 27 (97\%) than the roster-based measure (89\%) and that this event is taking place earlier, on average, than when using the roster-based measure (21 years vs. 22 years of age). Taking a closer look young adults' home-leaving pathways, just under three-quarters of those who ultimately leave the parental home at least once in this stage of the life course make their first transition via pathways labeled as “Other.” In this analysis, the “Other” category captures transitions to residential arrangements that are the focus of most home-leaving research: transitions to non-institutional living arrangements that are captured by the household roster, such as transitions into a house or apartment owned by the respondent or their partner (74\%).

However, over one-quarter of young adults exit the parental home via pathways not necessarily linked to such family or household transitions. Eighteen percent of young adults left for residential arrangements tied to their pursuit of postsecondary education (dormitories, fraternities/sororities), three percent moved to military barracks for service and training, two percent left for incarceration, and approximately three percent had not yet left by the age of 27 . The remainder of this analysis explores the empirical consequences of integration of perspectives on residential transitions and institutional contact in the transition to adulthood for our understanding this stage of the life course as well as racial/ethnic disparities in the nature of this important life event. 
Table 1. Analytic Sample

\begin{tabular}{|c|c|}
\hline & $\begin{array}{c}\text { Mean or } \\
\text { Proportion }\end{array}$ \\
\hline \multicolumn{2}{|l|}{ Social/Demographic Characteristics } \\
\hline Female & 0.485 \\
\hline Race/Ethnicity & \\
\hline White, Non-Hispanic & 0.684 \\
\hline Black, Non-Hispanic & 0.143 \\
\hline Hispanic & 0.126 \\
\hline Other, Non-Hispanic & 0.047 \\
\hline Parental Education (Years) & $\begin{array}{l}13.663 \\
(2.882)\end{array}$ \\
\hline 12 Years or Less & 0.440 \\
\hline 13 Years or More & 0.560 \\
\hline Age at $1^{\text {st }}$ Observation (in 1997) & $\begin{array}{l}14.348 \\
(1.502)\end{array}$ \\
\hline Rounds Observed & $\begin{array}{l}13.246 \\
(1.685)\end{array}$ \\
\hline \multicolumn{2}{|l|}{ Home-Leaving Characteristics } \\
\hline Roster-Based Measure & 0.893 \\
\hline Institution-Inclusive Measure & 0.967 \\
\hline \multicolumn{2}{|l|}{ Age at $1^{\text {st }}$ Home-Leaving ${ }^{+}$} \\
\hline Roster-Based Measure & $\begin{array}{l}21.554 \\
(2.889)\end{array}$ \\
\hline Institution-Inclusive Measure & $\begin{array}{l}20.511 \\
(2.963)\end{array}$ \\
\hline \multicolumn{2}{|l|}{ Pathway to $1^{\text {st }}$ Home-Leaving } \\
\hline Other & 0.737 \\
\hline College & 0.177 \\
\hline Military & 0.034 \\
\hline Jail/Prison & 0.018 \\
\hline Group Home/Homeless & 0.001 \\
\hline Not Yet Departed by 27 & 0.033 \\
\hline $\mathbf{N}$ & 6,843 \\
\hline
\end{tabular}

Notes: Standard deviations reported in parentheses. Estimates are weighted. ${ }^{+}$Indicates measures that apply only to those who have ever left the parental home over the study period, for which the sample sizes were 6,001 and 6,592 for the roster-based and institution-inclusive measures, respectively. 


\section{Cumulative Risks of First Home-Leaving by Age 27}

To examine how the inclusion of transitions to institutions might impact our understanding the risk and timing of first departures from the parental home in the transition to adulthood, I compare cumulative risks of first home-leaving estimated using cohort life tables and the roster-based and institution-inclusive definitions of home-leaving described above. Figure 1 presents the risk plots for these results, with a full presentation of the point estimates and their confidence intervals in Appendix Table A2. The discrepancy between the two risk curves is stark. The roster-based estimates indicate a gradual increase in first home-leaving with age over the transition to adulthood, with a slight acceleration in this trend in the early years of adulthood (beginning at age 18). With the inclusion of residential transitions to postsecondary, carceral, military, and other non-household/family institutions, however, the risk of first homeleaving spikes between the ages of 18 and 21, yielding higher cumulative risks of first homeleaving than the roster-based measure for the duration of the study period.

At the start of the study period when respondents are younger than 17 years of age, the cumulative risk of first home-leaving does not differ statistically across the two measures. However, by the late teens, the institution-inclusive measure yields substantially and statistically significantly higher estimates of first home-leaving; by age 18, the roster-based measure estimates that just under five percent of respondents have left the parental home for the first time; the institution-inclusive measure estimates that just over seven percent have left.

It would be reasonable to have expected that the inclusion of institutional transitions might have yielded higher risks of first home-leaving during ages in which young adults are first leaving for military service and higher education but that ultimately the two sets of estimates would converge, indicating that those who do not leave their parents' homes early in this life 
stage for institutions eventually "catch up" in their likelihoods of leaving the home for the first time as they make family and household transitions. However, the persisting discrepancy between the two sets of estimates indicates otherwise: at age 27, the cumulative risk of first home-leaving is 0.78 using the roster-based measure and nearly 10 percentage points higher using the institution-inclusive measure (0.87).

\section{Figure 1. Cumulative Risk of First Home-Leaving, by Measure}

Cumulative Risk

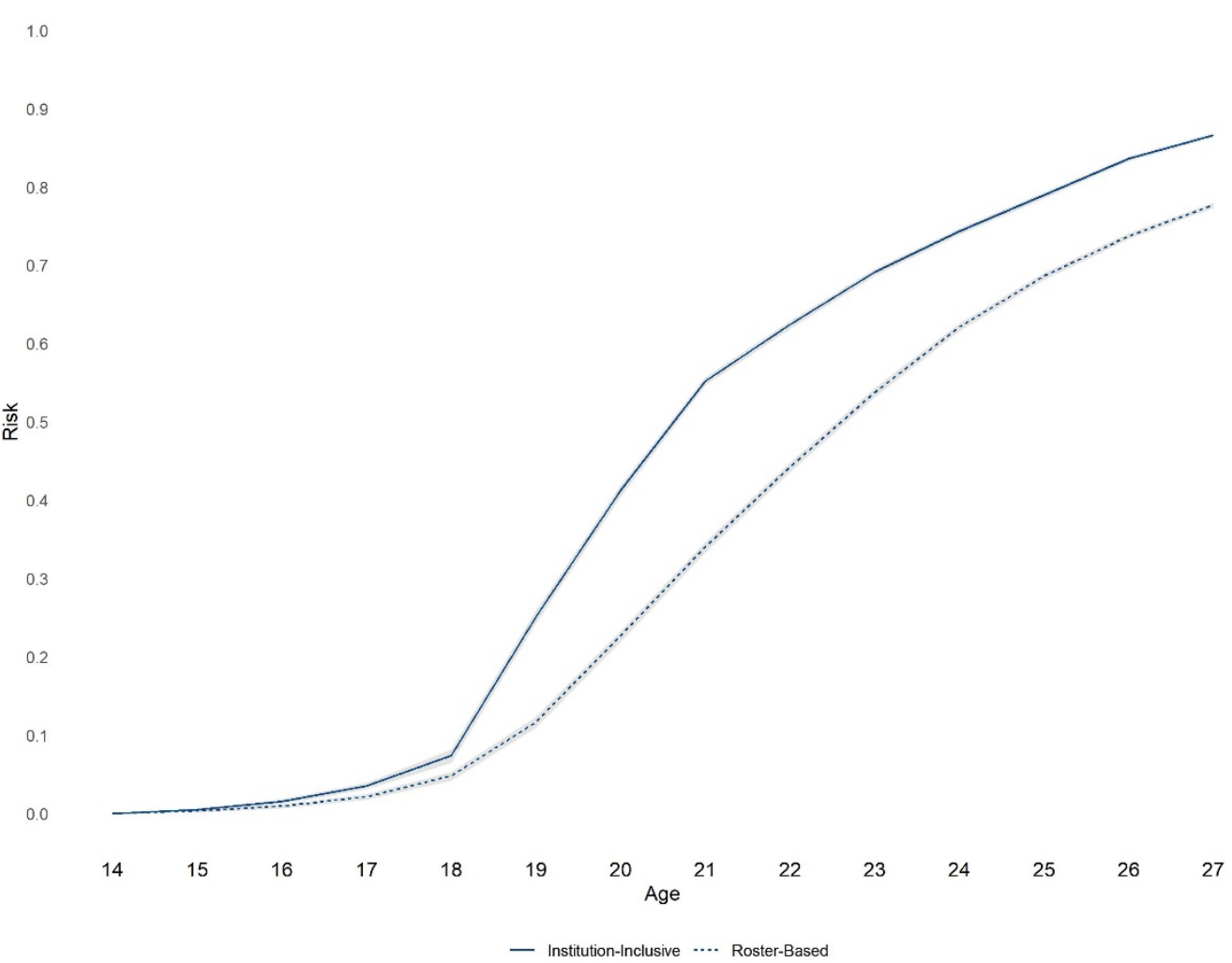

Notes: $\mathrm{N}=6,853$. Estimates are weighted.

\section{Racial/Ethnic Variation in First Home-Leaving}

The results discussed so far illustrate the implications of incorporating institutional transitions into our conceptualization and measurement of events constituting home-leaving in the transition to adulthood. However, it is possible that the salience of such experiences varies across social groups, meaning that institutions may be differentially impactful on home-leaving 
timing and risk across sociodemographic and economic groups. Given what we already know about inequalities in institutional contact and matriculation with respect to race/ethnicity and other dimensions of social difference, this is highly plausible (e.g. Pettit and Western 2004; Ovink and Kalogrides 2015).

To explore this possibility, I now turn to group-specific cumulative risk estimates using the roster-based and institution-inclusive measures of home-leaving by race/ethnicity, the results of which are presented in Figures 2 and 3, with corresponding point estimates and confidence intervals presented in Appendix Table A3. A comparison of the race/ethnicity-specific rosterbased and institution-inclusive cumulative risk estimates again shows that the incorporation of residential transitions to institutions yields higher estimates of the risk of home-leaving in the transition to adulthood and earlier first departures (Figure 2). This holds true for all racial/ethnic groups, although the degree to which the inclusion of institutions drives up home-leaving risks at earlier ages and by the end of the study period appears to differ across groups.

\section{Figure 2. Cumulative Risks of First Home-Leaving, by Measure and Race/Ethnicity}
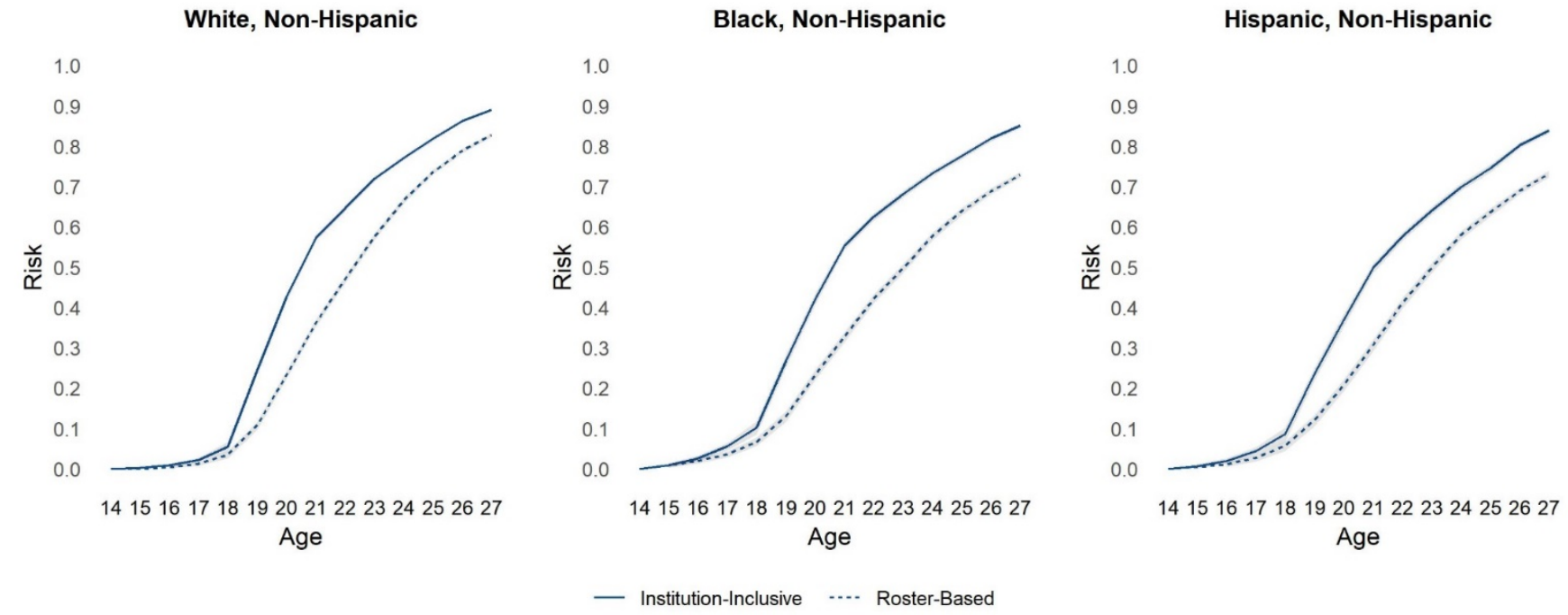

Notes: $\mathrm{N}=6,853$. Estimates are unweighted.

In addition to differences in estimates of cumulative risks across the two measures, the two measures vary in their description of racial differences or inequalities in home-leaving risks 
over this period. By re-arranging the race/ethnicity-specific cumulative risk curves to allow for comparisons within measure (i.e. roster-based or institution-inclusive measures of homeleaving), it is possible to examine whether the roster-based and institution-inclusive measures present different portraits of racial/ethnic differences in home-leaving timing, as shown in Figure 3. The left panel, which draws on the roster-based measure, shows that the timing of first departures from the parental home is notably different for White young adults than for those who are Black and Hispanic. Although White young adults were less likely to depart the parental home early in this stage of the life course, by the early twenties, there is a cross-over, with the cumulative risk of first home-leaving exceeding that of the other racial/ethnic groups for the duration of the period.

With the inclusion of institutional transitions, the cumulative risk of first home-leaving of White young adults again exceed those of the other two racial/ethnic groups in the latter half of this stage of the life course with a similar cross-over in the cumulative risks taking place slightly earlier, around age 19 (right panel, Figure 3). However, unlike in the roster-based estimation of home-leaving, the risks of departure among Black and Hispanic young adults in the middle period, converging only at the end of the study period. The institution-inclusive estimates, thus, estimate more racial/ethnic variation in home-leaving risks in the transition to adulthood than the White-non-White contrast identified in the roster-based analysis that is also well-documented in prior research on home-leaving. 


\section{Figure 3. Cumulative Risks of First Home-Leaving, by Race/Ethnicity}

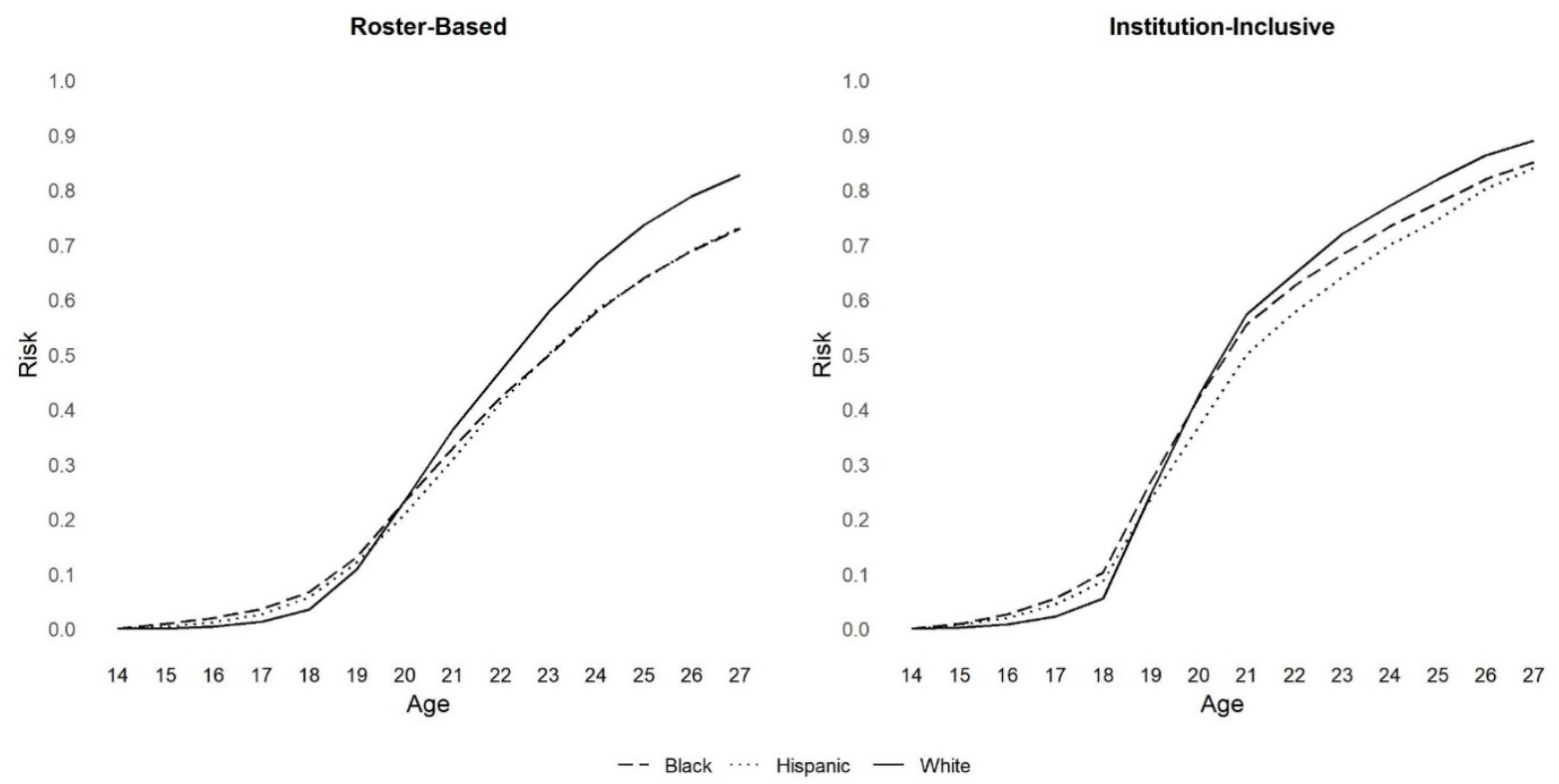

Notes: $\mathrm{N}=6,853$. Estimates are unweighted.

At this point in the study it is clear that the inclusion of institutions presents a somewhat different portrait of the timing, overall risk, and racial/ethnic differences in first departures from the parental home than a roster-based or family/household-based definition of home-leaving. But in addition to timing and cumulative risk, an institutional approach that considers the family/household as part of a suite of social institutions that shape the transition to adulthood will also pick up variation in the nature of young adults' home-leaving experiences. This variation in experience can be both symptomatic and predictive of stark inequalities in wellbeing and social inclusion/exclusion in the transition to adulthood that reverberate over the life course.

Using multinomial logistic regression models, I estimate likelihoods of experiencing different types of first departures from the parental home as functions of respondents’ racial/ethnic group identification (Model 1) as well as their sex and parental education group (Model 2). The results of these models, which also condition for age at the baseline survey (in 
1997) and the number of rounds for which respondents were observed in Rounds 1-11 of the NLSY97, are presented in Table 2.

Model 1, which, in addition to racial/ethnic identification, accounts only for technical measures of age at baseline and years observed indicates that for all three racial/ethnic groups, transition to an independent family/household or other residential arrangement identified exclusively via the household roster is most common (Table 4). However, among the remainder of young adults whose first home-leaving is linked to a different institution, there is distinct racial/ethnic patterning in the type of transition (Table 4). Home-leaving for college/university residential settings was the next most prevalent pathway for all groups, though most likely for those who are White (21\%) and least likely for those who identify as Hispanic (6\%). Departures for incarceration in a jail or prison and for a group home, shelter, or transition to homelessness were significantly more likely among those who identify as Black (4.3\% and 0.3\%, respectively). The only transition type that was not statistically more or less likely for any racial/ethnic group was for military service and training.

Model 2 adjusts further for individuals’ sex and parental education to account for genderbased and socioeconomic variation in certain types of institutional transitions that may also underlie the racial/ethnic differences identified in the baseline model. For example, studies of education have documented the increase of women's pursuit and attainment of postsecondary degrees and training and, more recently, their higher educational attainment relative to men and incarceration is disproportionately common among those of low income and less advantaged socioeconomic backgrounds (e.g. DiPrete and Buchmann 2006; Pettit and Western 2004). In these results, sex and parental education partly explain components of the racial/ethnic variation 
in first home-leaving to institutional contexts. However, even after accounting for these sociodemographic characteristics, substantial and meaningful racial/ethnic differences persist.

Net of sex and parental education, young adults of Hispanic ethnicity are statistically more likely than those who are White or Black to have their first departure from the parental home be to an independent family/household living arrangement. Although in the first model White, Black, and Hispanic respondents were all statistically different from one another in their likelihoods of first transitioning to a residential context linked to their postsecondary education, after adjusting for sex and parental education, those who are Hispanic emerge as distinct in their substantially and statistically lower likelihood of first home-leaving to collegiate residential settings ( $9 \%$ for Hispanics vs. $17 \%$ and $16 \%$ for Whites and Blacks, respectively). Young adults who are Black remain significantly more likely to transition from the parental home for the first time for incarceration; the White-Black difference in the likelihood of this transition type is very slightly diminished with additional covariate adjustment while the Hispanic-Black difference widens slightly from 2.6 to 3.2 percentage points. 
Table 2. Multinomial Regression Models of First Transition from the Parental Home

\begin{tabular}{|c|c|c|c|c|c|c|c|c|c|c|c|c|}
\hline \multirow[b]{3}{*}{ Race/Ethnicity } & \multicolumn{6}{|c|}{ Model 1} & \multicolumn{6}{|c|}{ Model 2} \\
\hline & Other & College & Military & $\begin{array}{c}\text { Jail/ } \\
\text { Prison }\end{array}$ & $\begin{array}{c}\text { Group } \\
\text { Home/ } \\
\text { Homeless }\end{array}$ & $\begin{array}{c}\text { Not Yet } \\
\text { Departed } \\
\text { by } 27 \\
\end{array}$ & Other & College & Military & $\begin{array}{c}\text { Jail/ } \\
\text { Prison }\end{array}$ & $\begin{array}{c}\text { Group } \\
\text { Home/ } \\
\text { Homeless }\end{array}$ & $\begin{array}{c}\text { Not Yet } \\
\text { Departed } \\
\text { by } 27\end{array}$ \\
\hline & & & & & & & & & & & & \\
\hline White & $\begin{array}{c}0.719^{\mathrm{H}} \\
(0.008)\end{array}$ & $\begin{array}{c}0.204^{\mathrm{B}, \mathrm{H}} \\
(0.007)\end{array}$ & $\begin{array}{c}0.035 \\
(0.003)\end{array}$ & $\begin{array}{l}0.013^{\mathrm{B}} \\
(0.002)\end{array}$ & $\begin{array}{l}0.001^{\mathrm{B}} \\
(0.001)\end{array}$ & $\begin{array}{c}0.029^{\mathrm{B}} \\
(0.003)\end{array}$ & $\begin{array}{c}0.742^{\mathrm{H}} \\
(0.007)\end{array}$ & $\begin{array}{l}0.180^{\mathrm{H}} \\
(0.006)\end{array}$ & $\begin{array}{c}0.034 \\
(0.003)\end{array}$ & $\begin{array}{c}0.015^{\mathrm{B}} \\
(0.002)\end{array}$ & $\begin{array}{c}0.001 \\
(0.001)\end{array}$ & $\begin{array}{c}0.028^{\mathrm{B}} \\
(0.003)\end{array}$ \\
\hline Black & $\begin{array}{l}0.747^{\mathrm{H}} \\
(0.010)\end{array}$ & $\begin{array}{c}0.133^{\mathrm{W}, \mathrm{H}} \\
(0.008)\end{array}$ & $\begin{array}{c}0.027 \\
(0.004)\end{array}$ & $\begin{array}{c}0.043^{\mathrm{W}, \mathrm{H}} \\
(0.005)\end{array}$ & $\begin{array}{c}0.003^{\mathrm{W}, \mathrm{H}} \\
(0.001)\end{array}$ & $\begin{array}{l}0.046^{\mathrm{W}} \\
(0.005)\end{array}$ & $\begin{array}{c}0.729^{\mathrm{H}} \\
(0.011)\end{array}$ & $\begin{array}{c}0.152^{\mathrm{H}} \\
(0.009)\end{array}$ & $\begin{array}{c}0.028 \\
(0.004)\end{array}$ & $\begin{array}{c}0.040^{\mathrm{W}, \mathrm{H}} \\
(0.004)\end{array}$ & $\begin{array}{c}0.003 \\
(0.001)\end{array}$ & $\begin{array}{l}0.047^{\mathrm{W}} \\
(0.005)\end{array}$ \\
\hline Hispanic & $\begin{array}{c}0.849^{\mathrm{W}, \mathrm{B}} \\
(0.009)\end{array}$ & $\begin{array}{c}0.056^{\mathrm{W}, \mathrm{B}} \\
(0.006)\end{array}$ & $\begin{array}{c}0.034 \\
(0.005)\end{array}$ & $\begin{array}{l}0.016^{\mathrm{B}} \\
(0.003)\end{array}$ & $\begin{array}{l}0.001^{\mathrm{B}} \\
(0.001)\end{array}$ & $\begin{array}{c}0.043 \\
(0.005)\end{array}$ & $\begin{array}{c}0.832^{\mathrm{W}, \mathrm{B}} \\
(0.010)\end{array}$ & $\begin{array}{l}0.071^{\mathrm{W}, \mathrm{B}} \\
(0.008)\end{array}$ & $\begin{array}{c}0.036 \\
(0.005)\end{array}$ & $\begin{array}{l}0.014^{\mathrm{B}} \\
(0.003)\end{array}$ & $\begin{array}{c}0.001 \\
(0.001)\end{array}$ & $\begin{array}{c}0.045 \\
(0.006)\end{array}$ \\
\hline $\begin{array}{l}\text { Age Covariates } \\
\text { Sex, Parental Education }\end{array}$ & \multicolumn{6}{|c|}{$\mathrm{X}$} & \multicolumn{6}{|c|}{ X } \\
\hline
\end{tabular}

Note: $\mathrm{N}=6,853 .{ }^{* * *} \mathrm{p}<0.001{ }^{* *} \mathrm{p}<0.01{ }^{*} \mathrm{p}<0.05$ Estimates are unweighted. Both models adjust for respondent age in 1997 and the age range for which the respondent is observed in the NLSY97. Results are reported as predicted probabilities, with standard errors in parentheses. Superscripts denote statistically significant differences from ${ }^{\mathrm{W}}$ White, ${ }^{\mathrm{B}}$ Black, and ${ }^{\mathrm{H}}$ Hispanic respondents at the 95-percent confidence level. 


\section{DISCUSSION}

This analysis of the NLSY97 highlights the importance of incorporating intermediate transitions away from the family in the transition to adulthood, namely, departures for higher education or military service and incarceration. The life table estimates presented here lead to two key conclusions. First, designations of “adult” vs. "non-adult” experiences and transitions hold implications for even basic descriptive conclusions about the timing and prevalence of key milestones such as leaving the parental home. The inclusion of institutional transitions to military service, incarceration, and pursuit of higher education, for example, indicates that young adults are both more likely to leave the parental home by the age of 27 and to do so earlier, than estimated when we privilege family/household transitions in our definition of qualifying departures from the parental home. This holds for young adults of all racial/ethnic backgrounds. Second, the inclusion of institutions leads us to varying conclusions about racial/ethnic patterning in the timing and cumulative risk of first home-leaving. Both the roster-based and institution-inclusive analyses indicate that White young adults are more likely to have left the parental home by age 27 and that there is a cross-over between the cumulative risks of White young adults and those who are Black and Hispanic. However, while the roster-based analysis identifies a unique profile for Whites' cumulative risk of first departure, the institution-inclusive analysis reveals more heterogeneity across all three racial/ethnic groups.

Multinomial logistic regression models in the final stage of analysis in this study reveal racial/ethnic differences that question whether the concept of a "timely" first departure from the parental home makes sense when the institutions young adults enter after first home-leaving have such dramatically different implications for their wellbeing. The life table analysis already shows that young adults who identify as Hispanic and non-Hispanic Black have higher risks of first 
home-leaving early in the transition to adulthood but that White young adults are cumulatively more likely to have left by age 27. However, these moves away from the family of origin are not necessarily indicative of positive progress into autonomy and adulthood, a fact that is revealed through the expansion of the definition of home-leaving to include institutional contact or transitions that do not conform to a middle-class conceptualization of the transition to adulthood. Specifically, among young adults who leave home by age 27, even after accounting for parental education, Black young adults have a significantly higher relative risk of making a first transition away for incarceration as opposed to residence at a college/university or military campus or for other housing changes compared with their White peers. Hispanic young adults are both significantly less likely to be moving away to live in educational or training-related residential contexts or to transition into incarceration. The implications of these racial and ethnic differences for immediate and later-life wellbeing are likely substantial.

Although these results provide new evidence of the divergent pathways of young adults, this study has limitations. First, despite the fact that the life table approach provides detailed accounting of the timing and prevalence of initial residential transitions, the annual nature of the NLSY data means that there are first exits from the parental home that may be missed between mobility periods, or rounds of data collection. This is particularly true for pathways to college residence and incarceration, which often occur for intervals of time that are shorter than a year or may be more or less likely to be captured at certain times of the year. Therefore, it is possible that these figures underestimate the likelihood and risk of young adults' first transitions from the parental home for these particular institutional contexts or misidentify higher-order departures $\left(2^{\text {nd }}\right.$ or $3^{\text {rd }}$ times leaving the parental home after an initial departure and return) as first homeleaving because the data are unable to pick up earlier residential changes. 
Second, the data allow me to identify types of pathways out of the parental home that do not disaggregate by detailed aspects of residential settings. However, the diversity of residential experiences across institutions and facilities make it difficult to comment on how the relationship between race, ethnicity, home-leaving destinations, and later life outcomes might be moderated by institution-specific characteristics such as the type of university or college, choice of college major or academic program, the incarceration facility type, sentence length, and exposure to solitary confinement. (Armstrong and Hamilton 2013; Arum 2000; Turney and Conner 2019; Wildeman et al. 2016). Further, because the sample is restricted to those who reported living with at least one parent at baseline, these analyses may be missing some of the most disadvantaged young adults, those who are homeless or in foster care earlier in adolescence and childhood. Finally, because this study's main objective is to offer a conceptual exploration of the incorporation of institutions in our analysis of home-leaving, it leaves exploration of mechanisms and returns to the parental home following institutional transitions to future work.

Despite these constraints, these analyses make two broad contributions to the existing literature on home-leaving and the transition to adulthood and variation therein with respect to race and ethnicity. The primary contribution of this study is to highlight the racial/ethnic differences in home-leaving trajectories away from the parental home. As a secondary contribution, these findings demonstrate the utility of a different approach to measuring homeleaving that integrates considerations of social institutions beyond the home and family of origin into the study of home-leaving. With the expansion of postsecondary education (Baum et al. 2013) and incarceration (Garland 2001; Western 2006) in the United States over the last several decades, documentation of differential exposure to and participation in these drastically different systems as part of the home-leaving process is important to our understanding of divergent 
trajectories in the life course. Although transitions to dormitories or higher education and incarceration may be intermediate stops in residential trajectories and temporary in nature, these contexts are nonetheless significant in terms of their implications for racial/ethnic inequality and their relationships with key steps towards family and household formation in early adulthood. 


\section{REFERENCES}

Armstrong, Elizabeth A., and Laura T. Hamilton. 2013. Paying for the Party: How College Maintains Inequality. Cambridge, MA: Harvard University Press.

Arum, Richard. 2000. "Schools and Communities: Ecological and Institutional Dimensions." Annual Review of Sociology 26:395-418. https://doi.org/10.1146/annurev.soc.26.1.395

Baum, Sandy, Charles Kurose, and Michael McPherson. 2013. “An Overview of American Higher Education.” Future of Children 23(1):17-39.

Berzin, Stephanie Conser, and Allison C. DeMarco. 2010. “Understanding the Impact of Poverty on Critical Events in Emerging Adulthood.” Youth \& Society 42(2):278-300. https://doi.org/10.1177/0044118X09351909.

Bollen, Kenneth A., Paul P. Biemer, Alan F. Karr, Stephen Tueller, and Marcus E. Berzofsky. 2016. “Are Survey Weights Needed? A Review of Diagnostic Tests in Regression Analysis.” Annual Review of Statistics and Its Applications 3:375-392. https://doi.org/ 10.1146/annurev-statistics-011516-012958

Britton, Marcus L. 2013. "Race/Ethnicity, Attitudes, and Living with Parents during Young Adulthood.” Journal of Marriage and Family 75(4):995-1013. https://doi.org/10.111/jomf.12042.

Dey, Judith G., and Charles R. Pierret. 2014. “Independence for Young Millennials: Moving Out and Boomeranging Back.” Monthly Labor Review. Washington, DC: U.S. Bureau of Labor Statistics.

DiPrete, Thomas Albert, and Claudia Buchmann. 2006. "Gender-Specific Trends in the Value of Education and the Emerging Gender Gap in College Completion.” Demography 43(1):124. https://doi.org/10.1525/ctx.2004.3.3.33 
Furstenberg, Frank F., Sheela Kennedy, Vonnie C. McLoyd, Rubén G. Rumbaut, and Richard A. Settersten, Jr. 2004. “Growing Up is Harder to Do.” Contexts 3(3):33-41. https://doi.org/10.1525/ctx.2004.3.3.33

Furstenberg, Frank F. 2010. “On A New Schedule: Transitions to Adulthood and Family Change.” Future of Children 20(1):67-87. https://doi.org/ 10.1353/foc.0.0038

Garland, David. 2001. The Culture of Control: Crime and Social Order in Contemporary Society. Chicago: University of Chicago Press.

Hogan, Dennis P., and Nan Marie Astone. 1986. “The Transition to Adulthood.” Annual Review of Sociology 12:109-130. https://doi.org/10.1146/annurev.so.12.080186.000545

Kelty, Ryan, Meredith Kelykamp, and David R. Segal. 2010. “The Military and the Transition to Adulthood.” Future of Children 20(1):181-207.

Goldscheider, Frances K., and Julie S. Davanzo. 1985. “Living Arrangements and the Transition to Adulthood.” Demography 22(4):545-563. https://doi.org/10.2307/2061587

Goldscheider, Frances K., and Julie S. Davanzo. 1986. “Semiautonomy and Leaving Home during Early Adulthood.” Social Forces 65(1):187-201. doi:10.2307/2578942

Goldscheider, Frances K., and Julie DaVanzo. 1989. "Pathways to Independent Living in Early Adulthood: Marriage, Semiautonomy, and Premarital Residential Independence.” Demography 26(4):597-614. https://doi.org/10.2307/2061260

Goldscheider, Frances, and Calvin Goldscheider. 1999. The Changing Transition to Adulthood: Leaving and Returning Home. Thousand Oaks, CA: Sage Publications.

Goldscheider,, Frances, Calvin Goldscheider, Patricia St. Clair, and James Hodges. 1999. “Changes in Returning Home in the United Changes, 1925-1985.” Social Forces 78(2):695-728. doi:10.2307/3005572 
Goldscheider, Frances K., and Linda J. Waite. 1993. New Families, No Families? The

Transformation of the American Home. Berkeley and Los Angeles, CA: University of California Press.

Greenwood, Major. 1926. “The Natural Duration of Cancer.” Reports of Public Health and Related Subjects, Vol. 33, HMSO, London.

Gutmann, Myron P., Sara M. Pullum-Piñon, and Thomas W. Pullum. 2002. “Three Eras of Young Adult Home Leaving in Twentieth-Century America.” Journal of Social History 35(3):533-576. doi: 10.1353/jsh.2002.0014

Herbert, Claire W., Jeffrey D. Morenoff, and David J. Harding. 2015. "Homelessness and Housing Insecurity among Former Prisoners.” The Russell Sage Foundation Journal of the Social Sciences, Special issue on "Severe Deprivation in America." 1(2):44-79. doi: 10.7758/rsf.2015.1.2.04

Hogan, Dennis P., and Nan Marie Astone. 1986. "The Transition to Adulthood.” Annual Review of Sociology 12:109-130. https://doi.org/10.1146/annurev.so.12.080186.000545

Houle, Jason N., and Cody Warner. 2017. "Into the Red and Back to the Nest? Student Debt, College Completion, and Returning to the Parental Home among Young Adults.” Sociology of Education 90(1):89-108. https://doi.org/10.1177/0038040716685873

Kahn, Joan R., Javier García-Manglano, and Frances Goldscheider. 2017. “Race, Family Status, and Young Women’s Residential and Financial Dependency: 1970 to 2010.” Journal of Family Issues 38(18):2567-2593. https://doi.org/10.1177/0192513X16657127

Kelty, Ryan, Meredith Kleykamp, and David R. Segal. 2010. “The Military and the Transition to Adulthood." Future of Children 20(1):181-207. doi: 10.1353/foc.0.0045

Lei, Lei, and Scott J. South. 2016. “Racial and Ethnic Differences in Leaving and Returning to 
the Parental Home: The Role of Life Course Transitions, Socioeconomic Resources, and Family Connectivity.” Demographic Research 34(4):109-142. doi:

10.4054/DemRes.2016.34.4

Massoglia, Michael, Glenn Firebaugh, and Cody Warner. 2013. "Racial Variation in the Effect of Incarceration on Neighborhood Attainment.” American Sociological Review 78(1):129.

McDaniel, Anne, Thomas A. DiPrete, Claudia Buchmann, and Uri Shwed. 2011. “The Black Gender Gap in Educational Attainment: Historical Trends and Racial Comparisons.” Demography 48(3):889-914. doi:10.1177/0003122412471669.

Mykyta, Laryssa. 2012. “Economic Downturns and the Failure to Launch: The Living Arrangements of Young Adults in the U.S. 1995-2011.” Social, Economic, and Household Statistics Division Working Paper 2012-24. Washington, DC: U.S. Census Bureau.

Ovink, Sarah M., and Demetra Kalogrides. 2015. “No Place Like Home? Familism and Latino/aWhite Differences in College Pathways.” Social Science Research 52:219-235. https://doi.org/10.1016/j.ssresearch.2014.12.018

Pettit, Becky, and Bruce Western. 2004. "Mass Imprisonment and the Life Course: Race and Class Inequality in U.S. Incarceration.” American Sociological Review 90(2):151-169. https://doi.org/10.1177/000312240406900201

Preston, Samuel H., Patrick Heuveline, and Michel Guillot. 2001. Demography: Measuring and Modeling Population Processes. Oxford: Blackwell Publishers.

Qian, Zhenchao. 2012. "During the Great Recession, More Young Adults Lived with Parents.” Census Brief prepared for Project US2010. Available at: 
http://www.s4.brown.edu/us2010.

Rank, Mark R., and Thomas A. Hirschl. 1999. "The Likelihood of Poverty across the American Adult Life Span.” Social Work 44(3):201-216. http://dx.doi.org/10.1093/sw/44.3.201

Raphael, Steven. 2007. "Early Incarceration Spells and the Transition to Adulthood,” in Danziger, Sheldon and Cecilia Elena Rouse (Eds.) The Price of Independence: The Economics of Early Adulthood, Russell Sage Foundation: New York, pp.278-306.

Ruggles, Steven. 2007. “The Decline of Intergenerational Coresidence in the United States, 1850 to 2000.” American Sociological Review 72(6):964-989. doi:10.1177/000312240707200606.

Rumbaut, Rubén. 2007. “Turning Points in the Transition to Adulthood: Determinants of Educational Attainment, Incarceration, and Early Childbearing among Children of Immigrants.” Ethnic and Racial Studies 28(6):1041-1086.

https://doi.org/10.1080/01419870500224349

Sandberg-Thoma, Sara E., Anastasia R. Snyder, and Bohyun Joy Jang. 2015. “Exiting and Returning to the Parental Home for Boomerang Kids.” Journal of Marriage and Family 77(3):1-13. https://doi.org/10.1111/jomf.12183

Schoenfeld, David. 1981. “The Asymptotic Properties of Nonparametric Tests for Comparing Survival Distributions.” Biometrika 68(1):316-319. https://doi.org/10.1093/biomet/68.1.316

Settersten, Richard A., and Barbara Ray. 2010. “What’s Going on with Young People Today? The Long and Twisting Path to Adulthood.” Future of Children 20(1):19-41.

Solon, Gary, Steven J. Haider, and Jeffrey Wooldridge. 2015. “What Are We Weighting For?” NBER Working Paper 18859. 
Treas, Judith, and Jeanne Batalova. 2011. "Residential Independence: Race and Ethnicity on the Road to Adulthood in Two U.S. Immigrant Gateways.” Advances in Life Course Research 16:13-24. https://doi.org/10.1016/j.alcr.2011.01.001

Turney, Kristin, and Emma Conner. 2019. “Jail Incarceration: A Common and Consequential Form of Criminal Justice Contact.” Annual Review of Criminology 2:265-290. https://doi.org/10.1146/annurev-criminol-011518-024601

U.S. Bureau of Labor Statistics, U.S. Department of Labor. 2012. National Longitudinal Survey of Youth 1997: Youth Questionnaire 97 (R1), Youth Instrument. Available at: https://www.nlsinfo.org/sites/nlsinfo.org/files/attachments/121128/nlsy97r1yinf.html

U.S. Bureau of Labor Statistics, U.S. Department of Labor. 2015. National Longitudinal Survey of Youth 1997 cohort, 1997-2013 (rounds 1-16). Produced by the National Opinion Research Center, the University of Chicago and distributed by the Center for Human Resource Research, The Ohio State University. Columbus, $\mathrm{OH}$.

U.S. Bureau of Labor Statistics, U.S. Department of Labor. Undated. "National Longitudinal Survey of Youth 1997: Figure 1. NLSY97 Independence Criteria.” Available at: https://www.nlsinfo.org/content/cohorts/nlsy97/topical-guide/Income\#independence (Accessed January 28, 2019).

U.S. Census Bureau. 2018. "Historical Living Arrangements of Adults: Table AD-3, by Age Group.” Data: Historical Living Arrangements of Adults. Available on: https://www.census.gov/data/tables/time-series/demo/families/adults.html (Updated November 2018). van den Berg, Lonneke, Matthijs Kalmijn, and Thomas Leopold. 2018. “Leaving and Returning Home: A New Approach to off-Time Transitions.” Journal of Marriage and Family 
https://doi.org/10.1111/jomf.12550

Vespa, Jonathan. 2017. The Changing Economics and Demographics of Young Adulthood:19752016. Current Population Report P20-579. Washington, DC: U.S. Census Bureau.

Wakefield, Sara, and Christopher Wildeman. 2013. Children of the Prison Boom: Mass Incarceration and the Future of American Inequality. New York: Oxford University Press.

Warner, Cody. 2015. “On the Move: Incarceration, Race, and Residential Mobility.” Social Science Research 52:451-464. http://dx.doi.org/10.1016/j.ssresearch.2015.03.009

Western, Bruce. 2006. Punishment and Inequality in America. New York: Russell Sage Foundation.

White, Lynn. 1994. “Coresidence and Leaving Home: Young Adults and their Parents.” Annual Review of Sociology 20:81-102. https://doi.org/10.1146/annurev.so.20.080194.000501

Wiemers, Emily E. 2014. “The Effect of Unemployment on Household Composition and Doubling Up.” Demography 41:2144-2178. doi: 10.1007/s13524-014-0347-0

Wildeman, Christopher, and Natalia Emanuel. 2014. “Cumulative Risks of Foster Care Placement by Age 18 for U.S. Children, 2000-2011.” PLoS ONE 9(3):e92785. https://doi.org/10.1371/journal.pone.0092785

Wildeman, Christopher, Kristin Turney, and Youngmin Yi. 2016. "Paternal Incarceration and Family Functioning: Variation across Federal, State, and Local Facilities.” ANNALS of the American Academy of Political and Social Science 665(1):80-97. https://doi.org/10.1177/0002716215625042 


\section{Appendix A. Supplementary Tables}

Table A1. Comparison of Full NLSY97 and Analytic Samples

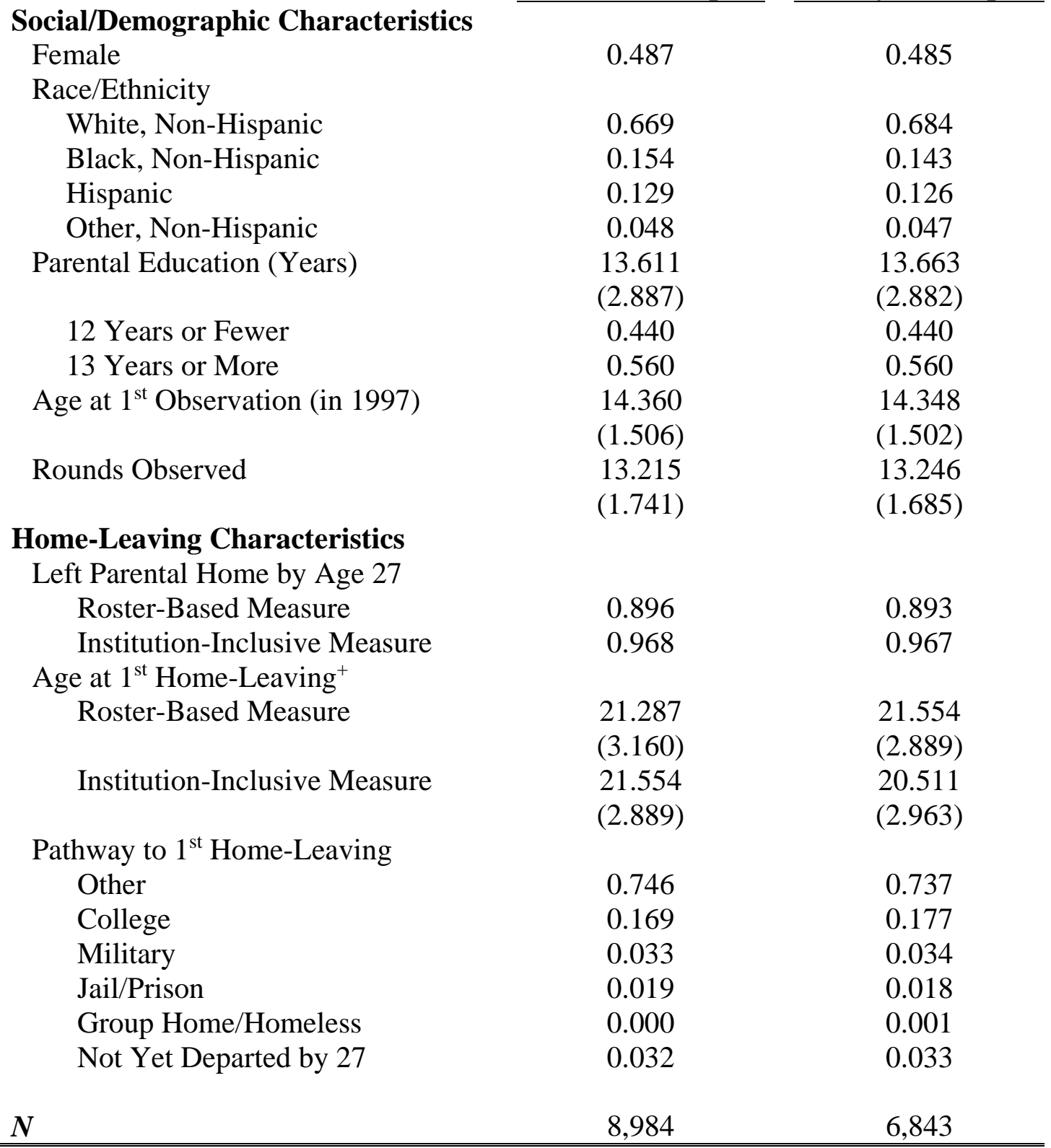

Notes: Estimates report weighted means and proportions with standard deviations reported in parentheses. ${ }^{+}$Indicates measures that apply only to those who have ever left the parental home over the study period, for which the sample sizes were 7,456 and 6,001 for the full and analytic samples using the roster-based measure, respectively, and 8,193 and 6,592 for the full and analytic samples using the institution-inclusive measures, respectively. 
Table A2. Age-Specific and Cumulative Risks of $1^{\text {st }}$ Departure from the Parental Home by Age 27, By Measure

\begin{tabular}{|c|c|c|c|c|}
\hline & \multicolumn{2}{|c|}{ Roster-Based Measure } & \multicolumn{2}{|c|}{ Institution-Inclusive Measure } \\
\hline & $\begin{array}{c}\text { Cumulative } \\
\text { Risk }\end{array}$ & $S E(c)$ & $\begin{array}{c}\text { Cumulative } \\
\text { Risk }\end{array}$ & $S E(c)$ \\
\hline 14 & 0.000 & {$[-0.001,0.001]$} & 0.000 & {$[-0.002,0.002]$} \\
\hline 15 & 0.003 & {$[0.001,0.005]$} & 0.005 & {$[0.002,0.007]$} \\
\hline 16 & 0.009 & {$[0.007,0.012]$} & 0.015 & {$[0.012,0.019]$} \\
\hline 17 & 0.022 & {$[0.018,0.025]$} & 0.036 & {$[0.031,0.040]$} \\
\hline 18 & 0.048 & {$[0.042,0.054]$} & 0.074 & {$[0.065,0.083]$} \\
\hline 19 & 0.117 & {$[0.109,0.124]$} & 0.251 & {$[0.242,0.260]$} \\
\hline 20 & 0.227 & {$[0.220,0.235]$} & 0.413 & {$[0.405,0.421]$} \\
\hline 21 & 0.341 & {$[0.334,0.348]$} & 0.553 & {$[0.547,0.559]$} \\
\hline 22 & 0.443 & {$[0.437,0.450]$} & 0.625 & {$[0.620,0.631]$} \\
\hline 23 & 0.539 & {$[0.532,0.545]$} & 0.693 & {$[0.688,0.697]$} \\
\hline 24 & 0.622 & {$[0.617,0.628]$} & 0.745 & {$[0.741,0.749]$} \\
\hline 25 & 0.687 & {$[0.682,0.692]$} & 0.791 & {$[0.787,0.795]$} \\
\hline 26 & 0.738 & {$[0.734,0.743]$} & 0.838 & {$[0.834,0.841]$} \\
\hline 27 & 0.778 & {$[0.774,0.782]$} & 0.868 & {$[0.864,0.871]$} \\
\hline
\end{tabular}

Notes: $\mathrm{N}=6,843$. Estimates are weighted. 
Table A3. Cumulative Risks of $1^{\text {st }}$ Departure from the Parental Home, By Measure and Race/Ethnicity

\begin{tabular}{|c|c|c|c|c|c|c|}
\hline & \multicolumn{2}{|c|}{ White, Non-Hispanic } & \multicolumn{2}{|c|}{ Black, Non-Hispanic } & \multicolumn{2}{|c|}{ Hispanic } \\
\hline & Roster-Based & Institution-Inclusive & Roster-Based & Institution-Inclusive & Roster-Based & Institution-Inclusive \\
\hline & 0.000 & 0.000 & 0.000 & 0.000 & 0.000 & 0.000 \\
\hline 14 & {$[-0.001,0.001]$} & {$[-0.001,0.001]$} & {$[-0.004,0.004]$} & {$[-0.004,0.004]$} & {$[-0.003,0.003]$} & {$[-0.004,0.004]$} \\
\hline & 0.000 & 0.002 & 0.008 & 0.009 & 0.003 & 0.007 \\
\hline 15 & {$[-0.002,0.002]$} & {$[-0.001,0.004]$} & {$[0.004,0.013]$} & {$[0.003,0.015]$} & {$[-0.001,0.008]$} & {$[0.001,0.013]$} \\
\hline 16 & $\begin{array}{c}0.004 \\
{[0.001,0.007]}\end{array}$ & $\begin{array}{c}0.008 \\
{[0.004,0.012]}\end{array}$ & $\begin{array}{c}0.019 \\
{[0.013,0.025]}\end{array}$ & $\begin{array}{c}0.026 \\
{[0.018,0.034]}\end{array}$ & $\begin{array}{c}0.012 \\
{[0.005,0.018]}\end{array}$ & $\begin{array}{c}0.020 \\
{[0.012,0.028]}\end{array}$ \\
\hline 17 & $\begin{array}{c}0.013 \\
{[0.008,0.018]}\end{array}$ & $\begin{array}{c}0.022 \\
{[0.016,0.028]}\end{array}$ & $\begin{array}{c}0.036 \\
{[0.028,0.044]}\end{array}$ & $\begin{array}{c}0.056 \\
{[0.046,0.066]}\end{array}$ & $\begin{array}{c}0.027 \\
{[0.018,0.036]}\end{array}$ & $\begin{array}{c}0.044 \\
{[0.034,0.055]}\end{array}$ \\
\hline 18 & $\begin{array}{c}0.035 \\
{[0.026,0.044]}\end{array}$ & $\begin{array}{c}0.055 \\
{[0.042,0.069]}\end{array}$ & $\begin{array}{c}0.067 \\
{[0.056,0.079]}\end{array}$ & $\begin{array}{c}0.103 \\
{[0.085,0.120]}\end{array}$ & $\begin{array}{c}0.057 \\
{[0.044,0.070]}\end{array}$ & $\begin{array}{c}0.086 \\
{[0.067,0.105]}\end{array}$ \\
\hline 19 & $\begin{array}{c}0.108 \\
{[0.097,0.120]}\end{array}$ & $\begin{array}{c}0.246 \\
{[0.233,0.259]}\end{array}$ & $\begin{array}{c}0.130 \\
{[0.116,0.145]}\end{array}$ & $\begin{array}{c}0.268 \\
{[0.252,0.285]}\end{array}$ & $\begin{array}{c}0.121 \\
{[0.107,0.136]}\end{array}$ & $\begin{array}{c}0.237 \\
{[0.219,0.254]}\end{array}$ \\
\hline 20 & $\begin{array}{c}0.233 \\
{[0.222,0.245]}\end{array}$ & $\begin{array}{c}0.426 \\
{[0.415,0.437]}\end{array}$ & $\begin{array}{c}0.233 \\
{[0.220,0.247]}\end{array}$ & $\begin{array}{c}0.421 \\
{[0.406,0.436]}\end{array}$ & $\begin{array}{c}0.209 \\
{[0.193,0.224]}\end{array}$ & $\begin{array}{c}0.369 \\
{[0.352,0.386]}\end{array}$ \\
\hline 21 & $\begin{array}{c}0.363 \\
{[0.352,0.373]}\end{array}$ & $\begin{array}{c}0.573 \\
{[0.565,0.581]}\end{array}$ & $\begin{array}{c}0.329 \\
{[0.315,0.342]}\end{array}$ & $\begin{array}{c}0.555 \\
{[0.544,0.566]}\end{array}$ & $\begin{array}{c}0.308 \\
{[0.293,0.324]}\end{array}$ & $\begin{array}{c}0.500 \\
{[0.487,0.513]}\end{array}$ \\
\hline 22 & $\begin{array}{c}0.471 \\
{[0.461,0.481]}\end{array}$ & $\begin{array}{c}0.647 \\
{[0.639,0.655]}\end{array}$ & $\begin{array}{c}0.422 \\
{[0.410,0.434]}\end{array}$ & $\begin{array}{c}0.625 \\
{[0.615,0.635]}\end{array}$ & $\begin{array}{c}0.412 \\
{[0.398,0.426]}\end{array}$ & $\begin{array}{c}0.577 \\
{[0.565,0.589]}\end{array}$ \\
\hline 23 & $\begin{array}{c}0.577 \\
{[0.568,0.586]}\end{array}$ & $\begin{array}{c}0.720 \\
{[0.714,0.727]}\end{array}$ & $\begin{array}{c}0.498 \\
{[0.486,0.510]}\end{array}$ & $\begin{array}{c}0.682 \\
{[0.673,0.691]}\end{array}$ & $\begin{array}{c}0.500 \\
{[0.487,0.514]}\end{array}$ & $\begin{array}{c}0.641 \\
{[0.630,0.652]}\end{array}$ \\
\hline 24 & $\begin{array}{c}0.666 \\
{[0.658,0.674]}\end{array}$ & $\begin{array}{c}0.771 \\
{[0.765,0.777]}\end{array}$ & $\begin{array}{c}0.577 \\
{[0.567,0.588]}\end{array}$ & $\begin{array}{c}0.733 \\
{[0.725,0.742]}\end{array}$ & $\begin{array}{c}0.581 \\
{[0.569,0.592]}\end{array}$ & $\begin{array}{c}0.699 \\
{[0.689,0.709]}\end{array}$ \\
\hline 25 & $\begin{array}{c}0.737 \\
{[0.730,0.743]}\end{array}$ & $\begin{array}{c}0.819 \\
{[0.813,0.825]}\end{array}$ & $\begin{array}{c}0.639 \\
{[0.630,0.649]}\end{array}$ & $\begin{array}{c}0.776 \\
{[0.768,0.785]}\end{array}$ & $\begin{array}{c}0.638 \\
{[0.627,0.649]}\end{array}$ & $\begin{array}{c}0.746 \\
{[0.736,0.757]}\end{array}$ \\
\hline 26 & $\begin{array}{c}0.789 \\
{[0.783,0.794]}\end{array}$ & $\begin{array}{c}0.863 \\
{[0.858,0.867]}\end{array}$ & $\begin{array}{c}0.689 \\
{[0.680,0.697]}\end{array}$ & $\begin{array}{c}0.819 \\
{[0.812,0.826]}\end{array}$ & $\begin{array}{c}0.690 \\
{[0.680,0.699]}\end{array}$ & $\begin{array}{c}0.803 \\
{[0.794,0.811]}\end{array}$ \\
\hline 27 & $\begin{array}{c}0.827 \\
{[0.822,0.832]}\end{array}$ & $\begin{array}{c}0.890 \\
{[0.886,0.894]}\end{array}$ & $\begin{array}{c}0.730 \\
{[0.722,0.737]}\end{array}$ & $\begin{array}{c}0.851 \\
{[0.844,0.57]}\end{array}$ & $\begin{array}{c}0.731 \\
{[0.722,0.741]}\end{array}$ & $\begin{array}{c}0.840 \\
{[0.831,0.848]}\end{array}$ \\
\hline
\end{tabular}

Notes: $\mathrm{N}=6,843$. Estimates are unweighted. 